\title{
Características Químicas e Digestibilidade in vitro de Silagens de Girassol ${ }^{1}$
}

\author{
Thierry Ribeiro Tomich², Lúcio Carlos Gonçalves ${ }^{3}$, Renata Graça Pinto Tomich ${ }^{4}$, José Avelino \\ Santos Rodrigues ${ }^{5}$, Iran Borges $^{3}$, Norberto Mario Rodriguez ${ }^{3}$
}

\begin{abstract}
RESUMO - As silagens de 13 cultivares de girassol (Helianthus annuus L.), produzidas com plantas contendo mais de $90 \%$ de grãos maduros, foram avaliadas quanto às características químicas e à digestibilidade in vitro da matéria seca (DIVMS). Os dados foram analisados segundo delineamento experimental inteiramente ao acaso e a comparação das médias, feita pelo teste SNK. O menor teor de matéria seca (19,8\%) foi obtido para o híbrido M737 e os maiores, para os híbridos Contiflor 7 (31,2\%) e Cargill $11(32,2 \%)$. Os valores de $\mathrm{pH}$ variaram de 4,1 a 5,5 e os teores nitrogênio amoniacal como porcentagem do nitrogênio total, de $5,9 \%$ a 14,6\%; as médias gerais para os conteúdos dos ácidos lático, acético e butírico foram de 7,1\%; 1,9\% e 0,06\%, respectivamente. O híbrido Rumbosol 91 apresentou a menor porcentagem de proteína bruta $(7,2 \%)$, enquanto teores acima de $9,0 \%$ foram notados para cinco cultivares. A média geral $(14,7 \%)$ de extrato etéreo (EE) foi maior que os valores normalmente observados para volumosos. Os teores de fibra em detergente neutro, fibra em detergente ácido (FDA) e lignina apresentaram médias gerais de 45,8; 35,7 e $6,4 \%$ e foram negativamente correlacionados com os valores de DIVMS (média geral de 49,8\%). Todos os cultivares apresentaram silagens com baixas concentrações médias de carboidratos solúveis residuais. De maneira geral, os altos conteúdos de FDA e de lignina e a DIVMS média de 49,8\% podem restringir a aplicação das silagens desses cultivares de girassol, para categorias mais exigentes, e o alto teor de EE pode limitar o nível de inclusão dessas silagens na dieta dos bovinos.
\end{abstract}

Palavras-chave: fermentação, silo experimental, valor nutritivo, volumoso

\section{Chemical Characterization and in vitro Digestibility of Sunflower Silages}

\begin{abstract}
Silages of thirteen cultivars of sunflower (Helianthus annuus L.) were evaluated for chemical characteristics and in vitro dry matter digestibility (IVDMD). The silages were produced when the plants presented above $90 \%$ of ripe grains. The experimental procedure followed a entirely randomized design and the mean values were compared by SNK test $(\mathrm{P}<.05)$. The smallest content of dry matter, 19.8\%, was obtained for the hybrid M737, and the highest were observed for Contiflor 7, with 31.2\%, and Cargill 11, with 32.2\%. The $\mathrm{pH}$ values varied from 4.1 up to 5.5, and the contents of ammonia-nitrogen as percentage of total nitrogen varied from $5.9 \%$ up to $14.6 \%$. The general averages obtained for lactic, acetic and butyric acids were of $7.1 \%, 1.9 \%$ and $0.06 \%$, respectively. The hybrid Rumbosol 91 presented the smallest percentage of crude protein, with $7.2 \%$, while contents above $9.0 \%$ were observed for five cultivars. The general average of ether extract (EE), 14.7\%, was quite high when compared to others contents usually obtained for roughage. The contents of neutral detergent fiber, acid detergent fiber (ADF) and lignin presented general averages of $45.8 \%, 35.7 \%$ and $6.4 \%$, and were negatively correlated to IVDMD (general average of 49.8\%). The silages presented low concentrations of residual soluble carbohydrates. The high contents of ADF and lignin, and the average of IVDMD (49.8\%) can restrict the application of the silages of those cultivars of sunflower for more the exigent categories of animals, and the high medium content of EE can limit the level of inclusion of those silages in bovine rations.
\end{abstract}

Key Words: experimental silos, fermentation, nutritional value, roughage

\section{Introdução}

O menor ciclo de produção, a resistência ao frio e a maior capacidade de extrair a água disponível no solo são características que têm possibilitado a produção da silagem de girassol em período de safrinha, como segunda safra anual, ou em locais onde a deficiência hídrica torna inviáveis culturas tradicionalmente utilizadas para esse propósito, como milho e sorgo. De acordo com Gonçalves et al. (1996), o cultivo do girassol, após a retirada da cultura de verão, com semeadura a partir de fevereiro, pode ser uma opção para a produção de forragem nas Regiões Sudeste e Centro Oeste do País. Castro et al.

\footnotetext{
1 Projeto parcialmente financiado pela FAPEMIG.

2 Pesquisador da Embrapa Pantanal, Centro de Pesquisa Agropecuária do Pantanal. Rua 21 de Setembro, 1880, Caixa Postal 109, Bairro Nossa Senhora de Fátima, CEP: 79320-900, Corumbá, MS. E.mail: thierry@cpap.embrapa.br

3 Professor da Escola de Veterinária da UFMG. Bolsista do CNPq. E.mail: luciocg@vet.ufmg.br; iran@vet.ufmg.br; norberto@vet.ufmg.br ${ }^{4}$ Estudante de Doutorado do Instituto de Ciências Biológicas da UFMG. Bolsista do CNPq. E.mail: retomich@icb.ufmg.br

5 Pesquisador da Embrapa Milho e Sorgo. E.mail: avelino@cnpms.embrapa.br
} 
(1996) consideraram que, nos sistemas já implantados, existem espaços físicos, temporais e/ou agronômicos, que podem ser ocupados pelo girassol, no estabelecimento de sistemas mais diversificados.

Sheaffer et al. (1977) observaram que, embora o girassol possa competir com o milho em termos de produção de matéria seca (MS), nos sistemas com duas safras anuais, a baixa qualidade da forragem é fator limitante ao uso de sua silagem. Henrique et al. (1998a) observaram teores de fibra bruta mais altos para a silagem de girassol, em relação às silagens de milho e de sorgo. Segundo Schingoethe et al. (1980), este conteúdo de fibra bruta, normalmente de 1,5 a 2 vezes mais alto, observado para a silagem de girassol, em relação à silagem de milho, reduz seu valor nutritivo. Vários autores relataram altos teores de óleo em silagens de girassol (Rezende et al., 2001a, Rezende et al., 2001b; Souza, 2002). Segundo Valdez et al. (1988a), o teor de óleo da silagem de girassol, até três vezes superior aos valores observados para silagens de milho, constitui um problema para a produção de silagem. McGuffey \& Schingoethe (1980) relatam que as maiores limitações para a utilização de silagens de girassol seriam os altos teores de fibra e de óleo. Almeida et al. (1995) e Henrique et al. (1998a) obtiveram conteúdos mais baixos de fibra em detergente neutro (FDN) e mais altos de proteína bruta (PB) para a silagem de girassol, quando comparada às silagens de milho e de sorgo, enquanto Tosi et al. (1975) e Rezende et al. (2001b) consideram que o girassol pode produzir silagens com composição química e valor nutritivo satisfatórios.

Além do valor nutritivo, a capacidade de conservação é outra característica que determina a adequação de uma cultura à ensilagem. De maneira geral, o termo "qualidade de silagem" está relacionado à eficácia do processo fermentativo para conservar a massa ensilada. Conforme Vilela (1998), características químicas como o valor de $\mathrm{pH}$, a concentração de nitrogênio amoniacal como porcentagem do nitrogênio total $\left(\mathrm{N}-\mathrm{NH}_{3} / \mathrm{NT}\right)$ e os teores de ácidos orgânicos são as variáveis normalmente empregadas para a avaliação da qualidade da fermentação de silagens.

Este trabalho foi conduzido com o objetivo de avaliar a qualidade do processo fermentativo e o valor nutritivo das silagens de 12 híbridos e de uma variedade de girassol, pela determinação de características químicas e da digestibilidade in vitro da MS.

\section{Material e Métodos}

Treze cultivares de girassol foram plantados em meados de fevereiro e colhidos e ensilados em maio, ou junho, quando apresentaram acima de 90\% de grãos maduros. Os híbridos AS243, AS603, Contiflor 3, M737, M742 e a variedade V2000 foram colhidos aos 104 dias após o plantio e os híbridos Cargill 11, Contiflor 7, DK180, M734, M738, Rumbosol 90 e Rumbosol 91, aos 116 dias. A colheita foi efetuada com corte rente ao solo e as plantas foram picadas em partículas com tamanho médio de dois centímetros, amostradas como forragem original e ensiladas em silos de laboratório. Foram produzidos 39 silos experimentais (três por cultivar), confeccionados com tubos de "PVC" (10 cm de diâmetro e $40 \mathrm{~cm}$ de comprimento), com tampas dotadas de válvulas tipo "Bunsen". A compactação da forragem foi feita com êmbolo de madeira, empregando pressão e número de movimentos para compactação similares em todos os silos. Para verificar a adequação desta compactação, a densidade da silagem foi determinada pela diferença no peso dos silos antes e depois da deposição da forragem.

Os silos foram abertos 56 dias após a vedação; as silagens foram retiradas, individualmente homogeneizadas e tiveram parte utilizada para a extração do "suco" e o restante seco em estufa de ventilação forçada a $65^{\circ} \mathrm{C}$ até peso constante. Imediatamente após a extração, as amostras dos "sucos" foram avaliadas quanto ao valor de $\mathrm{pH}$, em potenciômetro específico, e ao teor de nitrogênio amoniacal, por destilação com óxido de magnésio e cloreto de cálcio, empregando solução receptora de ácido bórico e titulação com ácido clorídrico a 0,1 N. Dez mililitros deste "suco" foram acondicionados em recipientes contendo $2 \mathrm{~mL}$ de ácido metafosfórico e congelados, para posterior avaliação dos teores de ácidos orgânicos. Após descongelamento, essas amostras foram centrifugadas (15 minutos a $4.000 \mathrm{rpm}$ ), filtradas em filtro de náilon com porosidade de $0,45 \mu \mathrm{m}$ e utilizadas para a dosagem dos ácidos lático, acético e butírico, por cromatografia gasosa. As amostras pré-secas foram processadas em moinho com peneira de $1 \mathrm{~mm}$ e utilizadas para determinação de MS a $105^{\circ} \mathrm{C}$, PB pelo método Kjeldhal e EE pelo processo Soxlet, segundo AOAC (2000), CS em álcool (Bailey, 1967), componentes da parede celular pelo método seqüencial (FDN, FDA e lignina), conforme Van 
Soest et al. (1991), e DIVMS, de acordo com Tilley \& Terry (1963). Para verificar a relação entre os conteúdos de carboidratos solúveis (CS) e de umidade da forragem e a extensão de utilização desses CS como substrato para a fermentação nos silos, também foram determinados os teores de MS e de CS nas forragens frescas.

Os dados foram analisados utilizando o programa Sistema para Análises Estatísticas e Genéticas (SAEG), de acordo com Euclydes (1983), empregando delineamento experimental inteiramente ao acaso, com 13 cultivares (tratamentos) e três silos (repetições), segundo o seguinte modelo estatístico:

$$
\mathrm{Y}_{\mathrm{ij}}=\mu+\mathrm{C}_{\mathrm{j}}+\sum_{\mathrm{ij}}
$$

em que $Y_{i j}=$ observação relativa à repetição $\mathrm{i}$ do cultivar $\mathrm{j} ; \mu=$ média geral; $\mathrm{C}_{\mathrm{j}}=$ efeito do cultivar $\mathrm{j}$ $(\mathrm{j}=1,2,3,4,5,6,7,8,9,10,11,12,13) ; \Sigma_{\mathrm{ij}}=$ erro experimental.

A comparação das médias foi feita pelo teste Student-Newman-Keuls (SNK), a 5\% de probabilidade, e os coeficientes de correlação entre as variáveis foram estimados pelo coeficiente de correlação de Pearson.

\section{Resultados e Discussão}

\section{Teor de matéria seca e densidade das silagens}

Na Tabela 1, são apresentados os conteúdos de MS e as densidades médias encontradas para as silagens. Para a colheita realizada com todos os cultivares apresentando acima de $90 \%$ dos grãos maduros, obteve-se grande variação nos teores de MS. Foram notados valores entre $19,6 \%$ para o híbrido $\mathrm{M} 737$, inferior $(\mathrm{P}<0,05)$ às demais médias, a $31,2 \%$ para o Contiflor 7 e $32,2 \%$ para o Cargill 11 , porcentagens superiores $(\mathrm{P}<0,05)$ às dos outros cultivares. Além da variação entre genótipos, a explicação para essas diferenças está na utilização de silos experimentais que não permitem o escoamento de efluentes e na escolha do critério para colheita que estabeleceu apenas o limite inferior de maturação fisiológica dos aquênios, associado à utilização de materiais com diferentes períodos de duração dos ciclos, e no fato de o corte ter sido realizado em apenas duas datas. Desse modo, alguns cultivares podem ter sido colhidos vários dias após a maturação total dos aquênios, período em que, de acordo com Castiglioni et al. (1994), a planta passa a perder umidade.

$\mathrm{O}$ teor de MS da forragem é um fator importante no processo da ensilagem e tem-se recomendado
Tabela 1 - Conteúdos médios de matéria seca e densidade das silagens de cultivares de girassol

Table 1 - Dry matter content and density of silages of sunflowers cultivars

\begin{tabular}{lcc}
\hline $\begin{array}{l}\text { Cultivar } \\
\text { Cultivar }\end{array}$ & $\begin{array}{c}\text { Matéria seca }(\%) \\
\text { Dry }\end{array}$ matter $(\%)$ & $\begin{array}{c}\text { Densidade }\left(\mathrm{kg} / \mathrm{m}^{3}\right) \\
\text { Density }\left(\mathrm{kg} / \mathrm{m}^{3}\right)\end{array}$ \\
\hline AS243 & $21,7^{\mathrm{E}}$ & $806,1^{\mathrm{A}}$ \\
AS603 & $21,9^{\mathrm{E}}$ & $787,2^{\mathrm{A}}$ \\
Cargill 11 & $32,2^{\mathrm{A}}$ & $595,8^{\mathrm{E}}$ \\
Contiflor 3 & $23,0^{\mathrm{D}}$ & $726,5^{\mathrm{B}}$ \\
Contiflor 7 & $31,2^{\mathrm{A}}$ & $510,7^{\mathrm{F}}$ \\
DK180 & $26,0^{\mathrm{BC}}$ & $632,4^{\mathrm{DE}}$ \\
M734 & $26,3^{\mathrm{BC}}$ & $637,8^{\mathrm{DE}}$ \\
M737 & $19,6^{\mathrm{F}}$ & $783,7^{\mathrm{A}}$ \\
M738 & $27,2^{\mathrm{B}}$ & $629,3^{\mathrm{DE}}$ \\
M742 & $23,5^{\mathrm{D}}$ & $738,6^{\mathrm{B}}$ \\
Rumbosol 90 & $26,8^{\mathrm{BC}}$ & $587,6^{\mathrm{E}}$ \\
Rumbosol 91 & $23,5^{\mathrm{D}}$ & $668,6^{\mathrm{CD}}$ \\
V2000 & $25,8^{\mathrm{C}}$ & $701,7^{\mathrm{CB}}$ \\
Média & 25,3 & 677,4 \\
Mean & & \\
CV (\%) & $2,3^{\mathrm{B}}$ & 3,4 \\
\hline
\end{tabular}

Médias seguidas por letras iguais na coluna não diferem pelo teste SNK $(p>0,05)$.

Means followed by identical letters in the same column do not differ by SNK test $(p>$.05).

conteúdos entre 30 e $35 \%$ para as silagens de milho e de sorgo. Esses valores estão relacionados, sobretudo, às possíveis limitações na ação de clotrídios (McDonald et al., 1991), na produção de efluentes (Xiccato et al., 1994) e na redução do consumo voluntário (Waldo, 1986), freqüentemente notadas em silagens baixas em MS. Em silagens com alto teor de MS, tendem a ocorrer danos por aquecimento e mofo (Van Soest, 1994). O baixo teor de MS é considerado um problema para a produção da silagem de girassol (McDonald et al., 1991), contudo, esse fato está relacionado à ensilagem em precoces períodos de desenvolvimento da planta, como observado por Tosi et al. (1975), que encontraram valores variando de $15,4 \%$ a $16,9 \%$ de MS, para os cortes com 94 dias após o plantio, e Rodrigues et al. (2001), com 17,5\% de MS, para o corte realizado com 99 dias de crescimento, para brácteas marrons e parte das folhas senescentes. Segundo Gonçalves \& Tomich (1999), silagens de girassol com mais altos teores de MS são produzidas quando a colheita é efetuada no período de maturação fisiológica dos aquênios (estádio $\mathrm{R}_{9} \mathrm{da}$ fase reprodutiva da planta), sendo observado por Câmara et al. (1999) que silagens com teores de MS acima de $30 \%$ são obtidas a partir desse estádio de desenvolvimento. Conteúdos de MS superiores a 
$30 \%$ foram obtidos nos trabalhos de McGuffey \& Schingoethe (1980), Schingoethe et al. (1980) e Hubbel et al. (1985), para cortes efetuados quando os capítulos apresentavam os grãos maduros. Entretanto, alguns estudos têm indicado que, objetivando-se a obtenção de uma forragem de melhor qualidade (Tosi et al., 1975; Edwards et al., 1978; Pereira et al. 2001; Rezende et al., 2001a; Rezende et al., 2001b), o conteúdo de MS adequado para a ensilagem do girassol pode situar-se abaixo dos $30 \%$ normalmente recomendados para as silagens tradicionais. Resultados com teores de MS intermediários foram relatados por Sneddon et al. (1981) e Thomas et al. (1982) (25,2 e $25,3 \%$, respectivamente, para silagens produzidas), quando a maioria das plantas apresentava a face posterior do capítulo amarela, brácteas marrons e algumas folhas secas, e Henrique et al. (1998a), com $24,5 \%$ e $25,6 \%$, respectivamente, para os girassóis C-11 e S-530, ensilados com os receptáculos apresentando coloração amarela. Neste experimento, as silagens com MS entre $30 \%$ e $35 \%$ foram obtidas apenas para os híbridos Cargill 11 e Contiflor 7, enquanto valores mais baixos, mas provavelmente ainda satisfatórios para o girassol (25\% a $30 \%)$, foram notados para outros cinco cultivares (DK180, M374, M738, Rumbosol 90 e V2000).

As silagens produzidas com os híbridos AS243 $\left(806,1 \mathrm{~kg} / \mathrm{m}^{3}\right), \operatorname{AS603}\left(787,2 \mathrm{~kg} / \mathrm{m}^{3}\right)$ eoM737 $\left(783,7 \mathrm{~kg} / \mathrm{m}^{3}\right)$ foram mais densas $(\mathrm{P}<0,05)$ que as dos outros cultivares, enquanto a silagem do híbrido Contiflor 7 $\left(510,7 \mathrm{~kg} / \mathrm{m}^{3}\right)$ apresentou a menor média $(\mathrm{P}<0,05)$. Segundo Van Soest (1994), os materiais com alto teor de umidade são mais fáceis de serem compactados e, como neste experimento, o tamanho de partícula e a pressão exercida sobre a massa ensilada - fatores que também são capazes de influenciar a densidade da silagem - não apresentaram variações perceptíveis entre os tratamentos; o teor de umidade foi, provavelmente, o principal responsável pelas diferenças encontradas. Além disso, foi observado baixo coeficiente de variação para a densidade $(3,4 \%)$ e obtida correlação alta e negativa $(\mathrm{r}=-0,88, \mathrm{P}<0,01)$ entre o teor de MS e a densidade das silagens, o que favorece essa afirmação. As silagens mal compactadas, geralmente, contêm oxigênio em excesso, enquanto o alto grau de compactação pode levar à produção excessiva de efluentes, ambos com efeitos prejudiciais à fermentação e ao valor nutritivo. Segundo Nussio (1997), silagens bem compactadas devem apresentar entre 600 e $800 \mathrm{~kg} / \mathrm{m}^{3}$, portanto, neste experimento, embora tenham sido notadas diferenças significativas entre tratamentos, foram produzidas silagens com compactação adequada para 11 dos 13 cultivares estudados.

Valor de pH e conteúdos de nitrogênio amoniacal $e$ de ácidos orgânicos

As médias obtidas para $\mathrm{pH}, \mathrm{N}-\mathrm{NH}_{3} / \mathrm{NT}$ e ácidos orgânicos das silagens são apresentadas na Tabela 2. A menor média de $\mathrm{pH}(4,1)$ foi encontrada para as silagens dos híbridos M737 e Rumbosol 91 , enquanto a maior $(5,5)$, para a silagem do híbrido Cargill 11. Valores de $\mathrm{pH}$ acima de 5,0 ainda foram notados para as silagens dos cultivares Contiflor 7, Rumbosol 90 e V2000. Os demais híbridos apresentaram resultados de 4,4 e 4,5. A conservação da forragem pela ensilagem baseia-se no processo de conservação em ácido, onde, conforme Muck \& Bolsen (1991), o decréscimo do $\mathrm{pH}$ pela fermentação da forragem ensilada leva à redução da atividade proteolítica, mediada por enzimas da própria planta, e cessa o crescimento de microrganismos anaeróbios indesejáveis, em especial, enterobactérias e clostrídios. De maneira geral, têm-se atribuído valores de $\mathrm{pH}$ entre 3,8 e 4,2 como adequados às silagens bem conservadas, uma vez que esses índices são, em regra, capazes de restringir a ação de enzimas proteolíticas da planta e de enterobactérias e clostrídios. Entretanto, de acordo com Muck (1988), para a avaliação do processo fermentativo, o valor de $\mathrm{pH}$ não deve ser tomado isoladamente, pois, em forragens com maiores teores de MS, o $\mathrm{pH}$ apresenta menor importância para a conservação da massa ensilada, enquanto forragens com menos de $25 \%$ de MS necessitam de baixos índices de $\mathrm{pH}$ para a inibição dos processos que levam à deterioração da forragem. Neste estudo, o valor de $\mathrm{pH}$ foi positivamente correlacionado ao conteúdo de MS $(\mathrm{r}=0,53 ; \mathrm{P}<0,01)$, indicando que as silagens mais úmidas apresentaram menores valores de $\mathrm{pH}$. Embora a média geral de $\mathrm{pH}$ das silagens tenha sido elevada $(4,7)$, utilizando-se a associação do teor de MS ao valor de $\mathrm{pH}$ para avaliação do processo fermentativo, pode-se considerar como bem conservadas as silagens produzidas pelos híbridos M737 e Rumbosol 91, que apresentaram teores de MS menores que $25 \%$, mas valores de $\mathrm{pH}$ abaixo de 4,2 , e as silagens dos híbridos DK180, M374 e M738, com teores de MS acima de $25 \%$ e valores de $\mathrm{pH}$ igual a 4,5 . 
Tabela 2 - Valores de pH e conteúdos de nitrogênio amoniacal em porcentagem do nitrogênio total $\left(\mathrm{N}-\mathrm{NH}_{3} / \mathrm{NT}\right)$ e de ácidos orgânicos das silagens de cultivares de girassol

Table 2 - $\quad \mathrm{pH}$ values and contents of ammonia-nitrogen as percentage of total nitrogen $\left(\mathrm{NH}_{3}-\mathrm{N} / \mathrm{TN}\right)$ and contents of organic acids of silages of sunflowers cultivars

\begin{tabular}{|c|c|c|c|c|c|}
\hline \multirow[t]{2}{*}{$\begin{array}{l}\text { Cultivar } \\
\text { Cultivar }\end{array}$} & \multirow[t]{2}{*}{$\mathrm{pH}$} & \multirow[t]{2}{*}{$\begin{array}{l}\mathrm{N}-\mathrm{NH}_{3} / \mathrm{NT} \\
\mathrm{NH}_{3}-\mathrm{N} / T N\end{array}$} & \multicolumn{3}{|c|}{$\begin{array}{c}\text { Ácidos orgânicos (\% MS) } \\
\text { Organic acids }(\% \text { DM) }\end{array}$} \\
\hline & & & $\begin{array}{l}\text { Lático } \\
\text { Lactic }\end{array}$ & $\begin{array}{l}\text { Acético } \\
\text { Acetic }\end{array}$ & $\begin{array}{c}\text { Butírico } \\
\text { Butyric }\end{array}$ \\
\hline AS243 & $4,5^{\mathrm{C}}$ & $10,0^{\mathrm{B}}$ & $7,8^{\mathrm{C}}$ & $2,5^{\mathrm{A}}$ & $0,00^{\mathrm{E}}$ \\
\hline AS603 & $4,4^{\mathrm{C}}$ & $8,0^{\mathrm{CDE}}$ & $9,7^{\mathrm{B}}$ & $1,9^{\mathrm{AB}}$ & $0,00^{\mathrm{E}}$ \\
\hline Cargill 11 & $5,5^{\mathrm{A}}$ & $9,2^{\mathrm{BC}}$ & $5,0^{\mathrm{D}}$ & $1,7^{\mathrm{B}}$ & $0,08^{\mathrm{CD}}$ \\
\hline Contiflor 3 & $4,5^{\mathrm{C}}$ & $8,1^{C D}$ & $8,4^{\mathrm{BC}}$ & $2,2^{\mathrm{AB}}$ & $0,00^{\mathrm{E}}$ \\
\hline Contiflor 7 & $5,3^{\mathrm{B}}$ & $8,3^{\mathrm{CD}}$ & $2,8^{\mathrm{E}}$ & $2,3^{\mathrm{AB}}$ & $0,00^{\mathrm{E}}$ \\
\hline DK180 & $4,5^{\mathrm{C}}$ & $6,8^{\mathrm{E}}$ & $7,9^{\mathrm{C}}$ & $1,5^{\mathrm{B}}$ & $0,05^{\mathrm{DE}}$ \\
\hline M734 & $4,5^{\mathrm{C}}$ & $7,3^{\mathrm{DE}}$ & $5,5^{\mathrm{D}}$ & $1,5^{\mathrm{B}}$ & $0,00^{\mathrm{E}}$ \\
\hline M737 & $4,1^{\mathrm{D}}$ & $8,5^{\mathrm{CD}}$ & $12,0^{\mathrm{A}}$ & $2,0^{\mathrm{AB}}$ & $0,00^{\mathrm{E}}$ \\
\hline M738 & $4,5^{\mathrm{C}}$ & $7,5^{\mathrm{DE}}$ & $7,4^{\mathrm{C}}$ & $1,7^{\mathrm{AB}}$ & $0,09^{\mathrm{C}}$ \\
\hline M742 & $4,4^{\mathrm{C}}$ & $9,0^{\mathrm{BC}}$ & $7,5^{\mathrm{C}}$ & $1,5^{\mathrm{B}}$ & $0,00^{\mathrm{E}}$ \\
\hline Rumbosol 90 & $5,2^{\mathrm{B}}$ & $10,1^{\mathrm{B}}$ & $4,6^{\mathrm{D}}$ & $1,9^{\mathrm{AB}}$ & $0,23^{\mathrm{B}}$ \\
\hline Rumbosol 91 & $4,1^{\mathrm{D}}$ & $5,9^{\mathrm{F}}$ & $9,0^{\mathrm{C}}$ & $1,8^{\mathrm{AB}}$ & $0,00^{\mathrm{E}}$ \\
\hline V2000 & $5,2^{\mathrm{B}}$ & $14,6^{\mathrm{A}}$ & $5,3^{\mathrm{D}}$ & $2,5^{\mathrm{A}}$ & $0,28^{\mathrm{A}}$ \\
\hline Média & 4,7 & 8,7 & 7,1 & 1,9 & 0,06 \\
\hline Mean & & & & & \\
\hline $\mathrm{CV}(\%)$ & 2,2 & 6,1 & 10,6 & 15,3 & 33,7 \\
\hline
\end{tabular}

Médias seguidas por letras iguais na coluna não diferem $(P>0,05)$ pelo teste SNK.

Means followed by identical letters in the same column did not differ $(P>05)$ by SNK test.

A mais baixa média de $\mathrm{N}-\mathrm{NH}_{3} / \mathrm{NT}$ das silagens $(5,9 \%)$ foi obtida para o híbrido Rumbosol 91 , enquanto a mais elevada $(14,6 \%)$, para a variedade V2000. Segundo Ohshima \& McDonald (1978), a forragem verde apresenta cerca de 75 a 90\% do nitrogênio total presente na proteína, o restante, chamado nitrogênio não-protéico, compreende principalmente aminoácidos livres e amidas, enquanto o teor de nitrogênio na forma de amônia, neste material, geralmente, é menor que $1 \%$ do nitrogênio total. De acordo com McKersie (1985), os compostos da proteólise e da degradação de aminoácidos formados durante o processo de fermentação da silagem, além de poder inibir o consumo e apresentar baixa eficiência na utilização do nitrogênio pelos ruminantes, alteram o curso da fermentação, impedindo rápida queda do $\mathrm{pH}$. Segundo Van Soest (1994), em silagens bem conservadas, os aminoácidos livres devem constituir a maior parte da fração nitrogenada não-protéica e a concentração de amônia deve ser baixa. Ohshima \& McDonald (1978), AFRC (1987) e Henderson (1993) citam valores máximos entre $8 \%$ e $11 \%$ de $\mathrm{N}-\mathrm{NH}_{3} / \mathrm{NT}$ como apropriados para as silagens bem conservadas. Considerando-se o valor máximo de $11 \%$ de $\mathrm{N}^{-\mathrm{NH}_{3}} / \mathrm{NT}$, excetuando a silagem da variedade V2000, as demais silagens produzidas pelos híbridos de girassol avaliados apresentaram valores médios de $\mathrm{N}-\mathrm{NH}_{3} / \mathrm{NT}$ abaixo deste limite e podem ser classificadas como bem conservadas quanto a esta característica.

$\mathrm{O}$ maior teor médio de ácido lático foi observado na silagem do híbrido M373 (12,0\%) e o menor $(2,8 \%)$, para o Contiflor 7. Os demais cultivares apresentaram silagens com teores de ácido lático de $4,6 \%$ a $9,7 \%$. A quantidade de ácido lático necessário para reduzir rapidamente o $\mathrm{pH}$ da massa ensilada, inibindo a atividade proteolítica e evitando fermentações indesejáveis, altera-se com a capacidade de tamponamento da forrageira e com o teor de umidade da silagem (Muck \& Bolsen, 1991). O teor de ácido lático foi negativamente correlacionado ao valor de $\mathrm{pH}(\mathrm{r}=-0,81 ; \mathrm{P}<0,01)$ e, com exceção do híbrido M734, os cultivares que produziram as silagens com os menores teores de ácido lático (abaixo de 6,0\%) foram os que também apresentaram silagens com valores de $\mathrm{pH}$ acima de 5,0. Embora a média geral de ácido lático $(7,1 \%)$ possa ser considerada adequada para silagens bem conservadas, o alto valor médio de $\mathrm{pH}(4,7)$ indica que, de maneira geral, a quantidade de 
ácido produzido não foi suficiente para reduzir o $\mathrm{pH}$ a níveis considerados adequados. Tosi et al. (1975) observaram que silagens de girassol com teores de ácido lático entre 3,36\% e 10,28\% apresentaram pH de 4,40 a 4,78 e concluíram que, embora ricas em ácido lático, a elevada capacidade de tamponamento da planta impediu a redução do $\mathrm{pH}$ das silagens.

Os teores de ácido acético apresentaram pequena variação $(\mathrm{P}<0,05)$ entre os cultivares, com média geral de $1,9 \%$. A presença de ácido acético em grandes proporções está relacionada à ação prolongada de enterobactérias e bactérias heterofermentativas, cujas fermentações acarretam maiores perdas de matéria seca e energia (Muck \& Bolsen, 1991). Segundo Moisio \& Heikonen (1994), se as concentrações de ácido lático, MS, PB, aminoácidos e amônia se mantivessem constantes, o aumento da concentração do ácido acético provocaria elevação do $\mathrm{pH}$. De acordo com McDonald et al. (1981), o consumo relaciona-se negativamente ao conteúdo de ácido acético da silagem. Portanto, para a avaliação da qualidade do processo fermentativo e a manutenção da qualidade do alimento, níveis reduzidos de ácido acético são desejáveis nas silagens. De maneira geral, os valores médios de ácido acético obtidos neste estudo $(1,5 \%$ a $2,5 \%$ ) podem ser considerados baixos e adequados às silagens bem conservadas.

Apenas as silagens produzidas pelos cultivares Cargill 11, DK180, M738, Rumbosol 90 e V2000 apresentaram níveis detectáveis de ácido butírico, com valores médios variando de 0,05 a $0,28 \%$. O conteúdo de ácido butírico reflete a extensão da atividade clostridiana sobre a massa ensilada, com efeito deletério na qualidade e redução da palatabilidade da silagem (Fisher \& Burns, 1987). Segundo Muck (1988), silagens com atividade de clostrídeos são caracterizadas por alto $\mathrm{pH}$ final e elevados teores de amônia e de ácido butírico. Neste trabalho, o teor de ácido butírico apresentou correlações positivas com o $\mathrm{pH}(\mathrm{r}=0,56 ; \mathrm{P}<0,01)$ e com o conteúdo de nitrogênio amoniacal $(\mathrm{r}=0,71 ; \mathrm{P}<0,01)$. De maneira geral, considera-se que silagens bem conservadas apresentam teores de ácido butírico abaixo de $0,1 \%$ da MS. Dessa forma, entre as silagens testadas neste estudo, apenas as produzidas pelo híbrido Rumbosol 90 e pela variedade V2000 não apresentaram boa qualidade de fermentação em relação a esta característica.
Conteúdos de carboidratos solúveis das forragens frescas e das silagens

Os teores médios obtidos para CS nos materiais originais e nas silagens constam na Tabela 3. Os teores deste componente nas forragens frescas variaram de $1,0 \%$, para a variedade V2000, a $6,1 \%$, para o híbrido Rumbosol 91. Além da capacidade de tamponamento da forragem, segundo Edwards et al. (1978), a quantidade de CS requerida para a produção de ácido necessária à conservação da massa ensilada depende do teor de umidade da forragem, variando de 2,0\% a 2,5\% do conteúdo de umidade da planta. Embora as diferentes metodologias utilizadas nessa análise impeçam comparações mais apropriadas, neste experimento, a média geral para a porcentagem de CS em relação à umidade das forragens frescas foi de $1,1 \%$ e apenas o híbrido Rumbosol 91 apresentou valor $(2,2 \%)$ acima desse limite mínimo, enquanto para os demais cultivares foram obtidas porcentagens entre 0,4 e $1,5 \%$. Contudo, conforme Harper et al. (1981) e McDonald et al. (1991), a

Tabela 3 - Conteúdo de carboidratos solúveis das forragens frescas e das silagens de cultivares de girassol

Table 3 - Soluble carbohydrates contents of fresh forage and silages of sunflowers cultivars

\begin{tabular}{lcc}
\hline Cultivar & \multicolumn{2}{c}{$\begin{array}{c}\text { Carboidratos solúveis }(\% \mathrm{MS}) \\
\text { Soluble carbohydrates }\end{array}$} \\
\cline { 2 - 3 } & $\begin{array}{c}\text { Forragem fresca } \\
\text { Fresh forage }\end{array}$ & $\begin{array}{c}\text { Silagem } \\
\text { Silage }\end{array}$ \\
\hline AS243 & 2,4 & $0,3^{\mathrm{BC}}$ \\
AS603 & 3,3 & $0,3^{\mathrm{BC}}$ \\
Cargill 11 & 1,2 & $0,1^{\mathrm{C}}$ \\
Contiflor 3 & 2,4 & $0,2^{\mathrm{C}}$ \\
Contiflor & 2,3 & $0,2^{\mathrm{C}}$ \\
DK180 & 3,4 & $0,3^{\mathrm{BC}}$ \\
M734 & 3,7 & $0,5^{\mathrm{A}}$ \\
M737 & 4,4 & $0,3^{\mathrm{BC}}$ \\
M738 & 2,4 & $0,5^{\mathrm{A}}$ \\
M742 & 2,5 & $0,4^{\mathrm{BB}}$ \\
Rumbosol 90 & 2,1 & $0,5^{\mathrm{A}}$ \\
Rumbosol 91 & 6,1 & $0,3^{\mathrm{BC}}$ \\
V2000 & 1,0 & $0,1^{\mathrm{C}}$ \\
Média & 2,9 & 0,3 \\
Mean & & \\
CV(\%) & - & 10,1
\end{tabular}

Médias seguidas por letras iguais na coluna não diferem $(p>0,05)$ pelo teste SNK.

Means followed by identical letters in the same column do not differ $(p>.05)$ by SNK test. 
planta do girassol apresenta níveis adequados de CS para sua conservação como silagem. Ainda, Tosi et al. (1975) observaram que os baixos níveis de CS encontrados para três cultivares de girassol não restringiram a produção de ácido lático, quando a planta foi ensilada em estádios iniciais de desenvolvimento. No presente trabalho, os teores de CS residuais nas silagens, após 56 dias de vedação dos silos, variaram de $0,1 \%$, para o híbrido Cargill 11 e para a variedade V2000, a 0,5\%, para os híbridos Rumbosol 90, M734 e M738, indicando sua extensa utilização durante a fermentação nos silos.

Conteúdos de proteina bruta e de extrato etéreo

As médias de PB encontradas para as silagens (Tabela 4) ficaram próximas aos valores observados por Silva et al. (1998), para o híbrido DK180. Menor conteúdo em PB foi notado por Sneddon et al. (1981), contudo, teores superiores são mais freqüentemente encontrados. Teores acima de $10 \%$ foram obtidos por Tosi et al. (1975), Bueno et al. (2001) e Resende et al. (2001a). Segundo Church (1988), efetiva fermentação microbiana no rúmen requer um mínimo de 7\% de proteína na dieta e, segundo Vilela (1998), o baixo

Tabela 4 - Conteúdos de proteína bruta e de extrato etéreo das silagens de cultivares de girassol

Table 4 - Crude protein and ether extract contents of silages of sunflowers cultivars

\begin{tabular}{lcc}
\hline $\begin{array}{l}\text { Cultivar } \\
\text { Cultivar }\end{array}$ & $\begin{array}{c}\text { Proteína bruta } \\
(\% \mathrm{MS}) \\
\text { Crude protein } \\
(\% \text { DM) }\end{array}$ & $\begin{array}{c}\text { Extrato etéreo } \\
(\% \mathrm{MS}) \\
\text { Ether extract } \\
(\% \text { DM) }\end{array}$ \\
\hline AS243 & $8,6^{\mathrm{B}}$ & $18,0^{\mathrm{AB}}$ \\
AS603 & $9,3^{\mathrm{A}}$ & $17,0^{\mathrm{ABC}}$ \\
Cargill 11 & $9,2^{\mathrm{A}}$ & $19,2^{\mathrm{A}}$ \\
Contiflor 3 & $8,0^{\mathrm{C}}$ & $13,5^{\mathrm{CDEF}}$ \\
Contiflor 7 & $7,9^{\mathrm{C}}$ & $10,6^{\mathrm{F}}$ \\
DK180 & $8,1^{\mathrm{C}}$ & $15,5^{\mathrm{BCD}}$ \\
M734 & $9,8^{\mathrm{A}}$ & $10,5^{\mathrm{F}}$ \\
M737 & $9,5^{\mathrm{A}}$ & $18,1^{\mathrm{AB}}$ \\
M738 & $9,8^{\mathrm{A}}$ & $13,7^{\mathrm{CDEF}}$ \\
M742 & $9,4^{\mathrm{A}}$ & $11,3^{\mathrm{DEF}}$ \\
Rumbosol 90 & $8,7^{\mathrm{B}}$ & $12,6^{\mathrm{DEF}}$ \\
Rumbosol 91 & $7,2^{\mathrm{D}}$ & $11,2^{\mathrm{EF}}$ \\
V2000 & $9,4^{\mathrm{A}}$ & $14,8^{\mathrm{BCDE}}$ \\
Média & $8,8^{\mathrm{C}}$ & 14,7 \\
Mean & 2,5 & 10,1 \\
CV $(\%)$ & & \\
\hline
\end{tabular}

Médias seguidas por letras iguais na coluna não diferem $(p>0,05)$ pelo teste SNK.

Means followed by identical letters in the same column do not differ $(p>.05)$ by SNK test.

R. Bras. Zootec., v.33, n.6, p.1672-1682, 2004 (Supl. 1) teor de nitrogênio da silagem de milho constitui fator limitante para sua utilização, principalmente para animais de mais altas exigências nutricionais. Embora não sejam apresentados dados sobre as proporções das frações nitrogenadas e disponibilidade do nitrogênio, vários trabalhos constataram níveis superiores de PB para a silagem de girassol, quando comparada à silagem de milho (Almeida et al., 1995; Henrique et al., 1998a; Bueno et al., 2001), ou em relação à silagem de sorgo (Almeida et al., 1995; Henrique et al., 1998a). Neste experimento, os valores de PB ficaram acima de 7\%, inclusive a média obtida para o híbrido Rumbosol 91 (7,2\%) foi a mais baixa $(\mathrm{P}<0,05)$ entre todos os cultivares.

Os teores médios de EE (Tabela 4) variaram de $10,5 \%$ a $19,2 \%$, com média geral de $14,7 \%$. Resultados próximos a esse valor médio foram obtidos por Valdez et al. (1988a), Valdez et al. (1988b) e Henrique et al. (1998a), para o girassol C-11. Resultado inferior foi obtido no experimento de Schingoethe et al. (1980), com 3,0\% para silagem de um cultivar de semente não-oleosa. Segundo McGuffey \& Schingoethe (1982), os grãos de girassol destinados à produção de óleo contêm de 35 a $45 \%$ de EE e, de acordo com Castiglioni et al. (1994), o enchimento dos aquênios termina com a maturação fisiológica da planta, apresentando teor definido nessa fase. Assim, os altos valores registrados para o EE deve-se ao fato de todos os cultivares usados neste experimento serem destinados à produção de óleo e de a colheita ter sido realizada com os materiais apresentando acima de $90 \%$ dos grãos maduros. Segundo Palmquist \& Jenkins (1980), as dietas convencionais de bovinos raramente contêm acima de 3,5\% de $\mathrm{EE}$, e altos níveis de gordura nessas dietas estão relacionados à redução da digestibilidade da fração fibrosa. Ainda de acordo com o NRC (2001), na maioria das situações, o total de gordura na dieta não deve ultrapassar de 6 a 7\% na MS, em razão de poder determinar reduções na fermentação ruminal, na digestibilidade da fibra e na taxa de passagem. Dessa forma, as silagens com os altos teores de EE devem ter sua inclusão limitada nas dietas para bovinos e indicam possível necessidade de associação com outros alimentos volumosos.

Componentes da parede celular e digestibilidade in vitro da matéria seca

A silagem do híbrido M737 apresentou o menor $(\mathrm{P}<0,05)$ teor de FDN $(37,7 \%)$, enquanto as dos híbridos M738, M742 e M734 apresentaram os maiores 
valores, 52,8; 51,5 e 50,6\%, respectivamente. Para os demais cultivares, os conteúdos foram de 40,7\% a $49,3 \%$ e a média geral $(45,8 \%)$ ficou um pouco acima dos teores encontrados em outros estudos (McGuffey \& Schingoethe, 1980; Thomas et al., 1982; Henrique et al., 1998a; Silva et al., 1998). A silagem do híbrido M737 também apresentou o menor $(\mathrm{P}<0,05)$ teor de FDA $(28,9 \%)$, enquanto os teores mais altos situaram-se entre $37,3 \%$ e $40,1 \%$. A média geral de FDA $(35,7 \%)$ está de acordo com as observações de Thomas et al. (1982), Almeida et al. (1995) e Henrique et al. (1998a), para a silagem do girassol C-11. Os conteúdos médios de lignina variaram de 5,2\% a $7,3 \%$, com a média geral de 6,5\% (Tabela 5). Resultados superiores, porém próximos a essa média, foram observados nos trabalhos de Valdez et al. (1988a) e Valdez et al. (1988b). Neste estudo, foram notadas correlações positivas $(\mathrm{P}<0,05)$ entre os teores de FDN e de FDA, assim como desses componentes com a lignina, indicando semelhança nos padrões de acúmulo desses conteúdos nos cultivares avaliados. Embora tenha-se reputado à silagem de girassol mais alto teor de fibra em relação às silagens de milho e de sorgo, esta afirmação é válida somente quando se refere à metodologia de fibra bruta para estimar a fração fibrosa. Isto porque estudos que avaliaram, simultaneamente, os conteúdos de FDN em silagens de milho ou de sorgo e em silagens de girassol sempre descrevem as menores proporções desta fração para o girassol (McGuffey \& Schingoethe, 1980; Valdez et al., 1988b; Almeida et al., 1995, Henrique et al., 1998a; Bueno et al., 2001). Como os teores de FDN das forragens são negativamente correlacionados com seu consumo e digestibilidade (Van Soest, 1994), não existindo outros fatores envolvidos, os alimentos com menores concentrações desse componente apresentariam maior consumo e melhor aproveitamento pelos animais. Dessa forma, considerando-se apenas a proporção de parede celular, a silagem de girassol poderia ser uma alternativa às silagens tradicionais. Contudo, conteúdos de FDA mais elevados são notados para o girassol em relação ao milho ou ao sorgo (McGuffey \& Schingoethe, 1980; Henrique et al. 1998a; Bueno et al., 2001), fração que apresenta a lignina entre seus componentes principais. Por sua vez, a lignina também é mais alta no girassol (Vandersall, 1976; McGuffey \& Schingoethe, 1980; Valdez et al., 1988a; e Bueno et al., 2001) e, segundo Jung et al. (1997), é negativamente correlacionada com as digestibilidades in vitro e in vivo da MS e da FDN. Portanto, de maneira geral, embora a FDN não esteja presente em altas proporções nas silagens de girassol, os relativos altos valores de FDA e de lignina podem restringir a qualidade de sua fração fibrosa e sua utilização para categorias mais exigentes.

A silagem do híbrido M737 apresentou o maior $(\mathrm{P}<0,05)$ valor de DIVMS $(56,7 \%)$, ao passo que a dos outros cultivares variaram de 46,9 a $51,5 \%$, com poucas diferenças significativas entre si (Tabela 5). $\mathrm{O}$ valor médio de 49,8\% ficou abaixo dos 59,6\%, observados por Schingoethe et al. (1980), trabalhando com um cultivar de girassol de semente não-oleosa. Também foi inferior às médias de 56,1 e 62,9\% encontradas por Rezende et al. (2001a), para as silagens de três cultivares colhidas, respectivamente, com 95 e 110 dias após a semeadura na safrinha. Foi menor também que o valor de 56,2\% obtido por Rezende et al. (2001b), para a média de seis cultivares colhidos aos 95 dias após a semeadura na safra. Entretanto, ficou próximo das médias de 49,4 e 48,1\% encontradas, respectivamente, por Rezende et al. (2001a) e Rezende et al. (2001b), para cortes com 125 e 110 dias após o plantio na safrinha e na safra. Dessa forma, no atual estudo, os valores de DIVMS relativamente baixos, obtidos para parte dos cultivares, poderiam estar relacionados a colheitas em estádios de maturação avançados ou à interferência do teor de EE, inibindo a digestibilidade da fibra. $\mathrm{O}$ efeito negativo do avanço do estádio de desenvolvimento da planta de girassol sobre a digestibilidade da forragem fresca foi verificado por Edwards et al. (1978), Harper et al. (1981) e Lloveras (1990). Pereira et al. (2001), Rezende et al. (2001a) e Rezende et al. (2001b) observaram redução nos valores de digestibilidade em estádios de maturação mais avançados da planta, em silagens de girassol.

Quanto ao efeito do conteúdo de óleo, Valdez et al. (1988b) encontraram incrementos na DIVMS e na digestibilidade in vitro da FDN, quando extraíram o óleo das silagens de milho, de milho/girassol e de girassol, proporcionais ao teor inicial de extrato etéreo da silagem. Contudo, Pentreath et al. (2002) não notaram aumento significativo na DIVMS, quando desengorduraram previamente as amostras de silagens de girassol com variação na relação capítulo/ caule+folhas. No presente estudo, o teor de EE foi positivamente correlacionado ao valor de DIVMS $(r=0,33 ; p=0,02)$, sugerindo que o maior teor de óleo nas silagens de certos cultivares não conduziu aos mais baixos valores de digestibilidade. Além disso, 
Tabela 5 - Conteúdos de fibra em detergente neutro (FDN), de fibra em detergente ácido (FDA) e de lignina e valores de digestibilidade in vitro da matéria seca (DIVMS) das silagens de cultivares de girassol

Table 5 - Neutral detergent fiber (NDF), acid detergent fiber (ADF) and lignin contents, and values of in vitro dry matter digestibility (IVDMD) of silages of sunflowers cultivars

\begin{tabular}{|c|c|c|c|c|}
\hline $\begin{array}{l}\text { Cultivar } \\
\text { Cultivar }\end{array}$ & FDN (\% MS) & FDA ( $\%$ MS $)$ & Lignina (\% MS) & DIVMS (\%) \\
\hline Cultivar & $N D F(\% D M)$ & $A D F(\% D M)$ & Lignin (\% DM) & $I V D M D(\%)$ \\
\hline AS243 & $43,4^{\mathrm{E}}$ & $33,9 \mathrm{DE}$ & $6,2^{\mathrm{BC}}$ & $47,1^{\mathrm{D}}$ \\
\hline AS603 & $40,7^{\mathrm{E}}$ & $31,5^{\mathrm{F}}$ & $5,4^{\mathrm{D}}$ & $51,1^{\mathrm{B}}$ \\
\hline Cargill 11 & $41,1^{\mathrm{E}}$ & $33,1^{\mathrm{EF}}$ & $5,7^{\mathrm{CD}}$ & $49,0^{\mathrm{CD}}$ \\
\hline Contiflor 3 & $46,7^{\mathrm{CD}}$ & $36,1^{\mathrm{BCD}}$ & $7,1^{\mathrm{AB}}$ & $49,9^{\mathrm{CD}}$ \\
\hline Contiflor 7 & $46,8^{\mathrm{CD}}$ & $36,1^{\mathrm{BCD}}$ & $6,9 \mathrm{AB}$ & $46,9^{\mathrm{D}}$ \\
\hline DK180 & $43,2^{\mathrm{E}}$ & $34,4^{\mathrm{DE}}$ & $6,4^{\mathrm{BC}}$ & $49,7^{\mathrm{BC}}$ \\
\hline M734 & $50,6^{\mathrm{AB}}$ & $39,4^{\mathrm{A}}$ & $6,9^{\mathrm{AB}}$ & $51,4^{\mathrm{B}}$ \\
\hline M737 & $37,7^{\mathrm{F}}$ & $28,9^{\mathrm{G}}$ & $5,2^{\mathrm{D}}$ & $56,7^{\mathrm{A}}$ \\
\hline M738 & $52,8^{\mathrm{A}}$ & $40,1^{\mathrm{A}}$ & $6,9^{\mathrm{AB}}$ & $49,4^{\mathrm{BCD}}$ \\
\hline M742 & $51,5^{\mathrm{AB}}$ & $39,7^{\mathrm{A}}$ & $6,8^{\mathrm{AB}}$ & $51,5^{\mathrm{B}}$ \\
\hline Rumbosol 90 & $49,3^{\mathrm{BC}}$ & $38,4^{\mathrm{AB}}$ & $7,3^{\mathrm{A}}$ & $48,6^{\mathrm{CD}}$ \\
\hline Rumbosol 91 & $47,7^{\mathrm{C}}$ & $37,3^{\mathrm{ABC}}$ & $7,1^{\mathrm{AB}}$ & $47,9^{\mathrm{CD}}$ \\
\hline V2000 & $44,0^{\mathrm{DE}}$ & $35,0^{\mathrm{CDE}}$ & $6,4^{\mathrm{BC}}$ & $48,9^{\mathrm{CD}}$ \\
\hline Média & 45,8 & 35,7 & 6,5 & 49,8 \\
\hline \multicolumn{5}{|l|}{ Mean } \\
\hline CV $(\%)$ & 3,1 & 3,2 & 5,3 & 1,9 \\
\hline
\end{tabular}

Médias seguidas por letras iguais na coluna não diferem $(p>0,05)$ pelo teste SNK. Means followed by identical letters in the same column did not differ $(p>.05)$ by SNK test.

foram notadas correlações negativas $(\mathrm{P}<0,05)$ entre conteúdos de MS e de componentes da parede celular com as porcentagens de DIVMS, indicando que, além das características inerentes aos cultivares, possivelmente, o estádio de desenvolvimento da planta, por ocasião da colheita, foi um fator capaz de influenciar a digestibilidade das suas silagens. Embora a silagem de girassol apresente, de maneira geral, valores inferiores de digestibilidade da MS, quando comparada às silagens de milho (Valdez et al., 1988a; Valdez et al., 1988b; Henrique et al., 1998b) e de sorgo (Henrique et al., 1998b), deve-se considerar que a silagem de girassol pode conter cerca de 1,7 a 3,1 vezes mais matéria mineral que as outras (McGuffey \& Schingoethe, 1980; Valdez et al., 1988b; Henrique et al., 1998a; Bueno et al., 2001), e a avaliação da digestibilidade da matéria orgânica pode ser uma análise mais adequada, quando o objetivo é comparar essas forragens.

\section{Conclusões}

Em média, os cultivares de girassol estudados produziram silagens com alto valor de $\mathrm{pH}$, mas os conteúdos de $\mathrm{N}_{-} \mathrm{NH}_{3} / \mathrm{NT}$ e de ácidos orgânicos observados são indicativos de silagens bem conservadas. Os teores relativamente altos de FDA e de lignina e a DIVMS média de $49,8 \%$ podem restringir a utilização das silagens avaliadas para categorias mais exigentes. $O$ alto teor de EE constitui fator limitante para o uso das silagens desses cultivares como volumoso único na dieta de bovinos e indica a possível necessidade de associação com outros alimentos volumosos.

\section{Agradecimento}

À Escola de Veterinária da Universidade Federal de Minas Gerais e à Embrapa Milho e Sorgo, pela possibilidade de realização deste trabalho.

\section{Literatura Citada}

AGRICULTURAL AND FOOD RESEARCH COUNCIL AFRC. Technical commitee on responses to nutrients. Report n.2, Characterisation of feedstuffs: nitrogen. Nutrition Abstracts and Reviews, Serie B, v.57, n.12, p.713-736, 1987.

ALMEIDA, M.F.; Von TIESENHAUSEN, I.M.E.V.; AQUINO, L.H. et al. Composição química e consumo voluntário das silagens de sorgo, em dois estádios de corte, girassol e milho para ruminantes. Ciência e Prática, v.19, n.3, p.315-321, 1995.

ASSOCIATION OF OFFICIAL ANALYTICAL CHEMISTS AOAC. Official methods of analysis. 16.ed. Washington: AOAC, 1995. 2000p. 
BAILEY, R.W. Quantitative studies of ruminant digestion. II. Loss of ingested plant carbohydrates from the reticulerumen. New Zealand Journal of Agricultural Research, v. 10, n.1, p. $15-32,1967$

BUENO, M.S.; FERRARI JR., E.; LEINZ, F.F. et al. Silagens de milho ou de girassol com diferentes proporções de ração concentrada na dieta de ovinos. In: REUNIÃO ANUAL DA SOCIEDADE BRASILEIRA DE ZOOTECNIA, 38., 2001, Piracicaba. Anais... Piracicaba: Sociedade Brasileira de Zootecnia, 2001. p.1296-1297.

CÂMARA, G.M.S.; SILVA, S.C.; MATTIAZZI, P. et al. Determinação do momento ideal de colheita de girassol (Helinthus annuus L.) para ensilagem durante a safrinha de 1998. In: REUNIÃO NACIONAL DE PESQUISA DE GIRASSOL, 13., 1999, Itumbiara. Anais... Londrina: Embrapa Soja, 1999. p.126-129.

CASTIGLIONI, V.B.R.; BALLA, A.; CASTRO, C. et al. Fases de desenvolvimento da planta do girassol. Londrina: Embrapa-CNPSo, 1994. 24p. (Documentos, 58)

CASTro, C.; CASTIGLIONI, V.B.R.; BALlA, A. et al. A cultura do girassol: tecnologia de produção. Londrina: Embrapa - CNPSO, 1996. 16p. (Documentos, 67)

CHURCH, D. C. El ruminant: fisiologia digestiva e nutricíon. Zaragoza: Acribia, 1988. 641p.

EDWARDS, R.A.; HARPER, F.; HENDERSON, A.R. et al. The potential of sunflowers as a crop for ensilage. Journal of Science and Food Agriculture, v.29, n.2, p.332-338, 1978.

EUCLYDES, R.F. Manual de utilização de programa SAEG (Sistema para Análises Estatísticas e Genéticas). Viçosa: UFV, 1983. 59p.

FISHER, D.S.; BURNS, J.C. Quality analysis of summerannual forages. II. Effects of carbohydrate constituents on silage fermentation. Agronomy Journal, v.79, n.2, p.242-248, 1987.

GONÇALVES, L.C., SILVA, F.F.; CORREA, C.E.S. et al. Produtividade e teor de matéria seca de girassol (Helianthus annus) cultivado em diferentes épocas do ano e colhido em diferentes estágios vegetativos. In: REUNIÃO ANUAL DA SOCIEDADE BRASILEIRA DE ZOOTECNIA, 33., 1996, Fortaleza. Anais... Fortaleza: Sociedade Brasileira de Zootecnia, 1996. p.377-379.

GONÇALVES, L.C.; TOMICH, T.R. Utilização do girassol como silagem para alimentação bovina. In: REUNIÃO NACIONAL DE PESQUISA DE GIRASSOL, 13., 1999, Itumbiara. Londrina: Embrapa Soja, 1999. p.21-30.

HARPER, F.; DONALDSON, E.; HENDERSON, A.R. et al. The potential of sunflower as a crop for ensilage and zero grazing in northern Britain. Journal of Agricultural Science, v.96, n.1, p.45-53, 1981.

HENDERSON, N. Silage additives. Animal Feed Science and Technology, v.45, n.1, p.35-56, 1993.

HENRIQUE, W.; ANDRADE, J.B.; SAMPAIO, A.A.M. Silagem de milho, sorgo, girassol e suas consorciações. II. Composição bromatológica. In: REUNIÃO ANUAL DA SOCIEDADE BRASILEIRA DE ZOOTECNIA, 35., 1998, Botucatu. Anais... Botucatu: Sociedade Brasileira de Zootecnia, 1998a. v.2., p.379-381.

HENRIQUE, W.; ANDRADE, J.B.; SAMPAIO, A.A.M. Silagem de milho, sorgo, girassol e suas consorciações. III. Coeficientes de digestibilidade. In: REUNIÃO ANUAL DA SOCIEDADE BRASILEIRA DE ZOOTECNIA, 35., 1998, Botucatu. Anais... Botucatu: Sociedade Brasileira de Zootecnia, 1998b. v. 2 , p. 382-384
HUBBEL, D.S.; HARRISON, K.F.; DANIELS, L.B. et al. A comparison of corn silage and sunflower silage for lactating Jersey cows. Arkansas Farm Research, v.34, n.1, p.7, 1985.

JUNG, H.G.; MERTENS, D.R.; PLANE, A.J. Correlation of acid detergent and Klason lignin with digestibility of forage dry matter and neutral detergent fiber. Journal of Dairy Science, v.80, n.8, p.1622-1628, 1997.

LLOVERAS, J. Dry matter yield and nutritive value of four summer annual crops in north-west Spain (Galicia). Grass and Forage Science, v.45, n.3, p.243-248, 1990.

McDONALD, P.; HENDERSON, A.R.; HERON, S. The biochemistry of silage. 2.ed. Marlow: Chalcombe Publications, 1991. 340p.

McGUFFEY, R.K.; SCHINGOETHE, D.J. Feeding value of high oil variety of sunflowers as silage to lactating dairy cows. Journal of Dairy Science, v.63, n.7, p.1109-1113, 1980.

McGUFFEY, R.K.; SCHINGOETHE, D.J. Whole sunflower seeds for high producing dairy cows. Journal of Dairy Science, v.65, n.8, p.1479-1483, 1982.

McKERSIE, B.D. Effect of $\mathrm{pH}$ on proteolysis in ensiled legume forage. Agronomy Journal, v.77, n.1, p.81-86, 1985.

MOISIO, T.; HEIKONEN, M. Latic acid fermentation in silage preserved with formic acid. Animal Feed Science and Technology, v.47, n.1, p.107-124, 1994.

MUCK, R.E.; BOLSEN, K.K. Silage preservation and additive products. In: BOLSEN, K.K.; BAYLOR, J.E.; McCUllough, M.E. (Eds.) Field guide and silage management in North America. West Des Moines: National Feed Ingredients Association, 1991. p.105-126.

MUCK, R.E. Factores influencing silage quality and their implications for management. Journal of Dairy Science, v.71, n.11, p.2992-3002, 1988.

NATIONAL RESEARCH COUNCIL - NRC. Nutrient requirements of dairy cattle. 7.ed. Washington: National Academy Press, 2001. 362p.

NUSSIO, L.G. Produção de silagem de sorgo. In: MANEJO CULTURAL DO SORGO PARA FORRAGEM. Sete Lagoas: Embrapa-CNPMS, 1997. p.53-55. (Circular Técnica, 17)

OHSHIMA, M.; McDONALD, P. A review of changes in nitrogenous compounds in herbages during ensiling. Journal of Science and Food Agriculture, v.29, n.6, p.497-505, 1978.

PALMQUIST, D.L.; JENKINS, T. C. Fat in lactation rations: a review. Journal of Dairy Science, v.63, n.1, p.1-14, 1980.

PENTREATH, M.; NOGUERA, J.R.R.; GONÇALVES, L.C. et al. Digestibilidade in vitro do material integral e desengordurardo de quatro cultivares de girassol Helianthus annuus L. ensilados com diferentes proporções da planta. In: REUNIÃO ANUAL DA SOCIEDADE BRASILEIRA DE ZOOTECNIA, 39., 2002. Recife. Anais... São Paulo: Gmosis, 2002. CD-ROM. Nutrição de ruminantes.

PEREIRA, L.G.R.; MAURÍCIO, R.M.; GONÇALVES, L.C. et al. Avaliação das silagens de quatro genótipos de girassol ensilados em quatro diferentes épocas pela técnica in vitro de produção de gás. In: REUNIÃO ANUAL DA SOCIEDADE BRASILEIRA DE ZOOTECNIA, 38., 2001, Piracicaba. Anais... Piracicaba: Sociedade Brasileira de Zootecnia, 2001. p. $1340-1342$.

REZENDE, A.V.; EVANGELISTA, A.R.; SANTOS, R.V. et al. Qualidade da silagem de girassol (Helianthus annuus L.) 1. diferentes idades de maturação fisiológica na safrinha. In: REUNIÃO ANUAL DA SOCIEDADE BRASILEIRA DE ZOOTECNIA, 38., 2001, Piracicaba. Anais... Piracicaba: Sociedade Brasileira de Zootecnia, 2001a. p.231-232. 
REZENDE, A.V.; EVANGELISTA, A.R.; SIQUEIRA, G.R. et al. Avaliação do valor nutritivo da silagem de girassol (Helianthus annuus L.) em diferentes épocas de corte na safra. In: REUNIÃO ANUAL DA SOCIEDADE BRASILEIRA DE ZOOTECNIA, 38., 2001, Piracicaba. Anais... Piracicaba: Sociedade Brasileira de Zootecnia, 2001b. p.234-236.

RODRIGUES, P.H.M.; ANDRADE, S.J.T.; ALMEIDA, T.F. et al. Valor nutritivo de silagens inoculadas com bactérias ácido-láticas. 3. Inoculação da silagem de girassol. In: REUNIÃO ANUAL DA SOCIEDADE BRASILEIRA DE ZOOTECNIA, 38., 2001, Piracicaba. Anais... Piracicaba: Sociedade Brasileira de Zootecnia, 2001. p.915-916.

SCHINGOETHE, D.J.; SKYBERG, E.W.; ROOK, J.A. Chemical composition of sunflower silage as influenced by additions of urea, dried whey and sodium hydroxide. Journal of Animal Science, v.50, n.4, p.529-625, 1980.

SHEAFFER, C.C.; McNEMAR, J.H.; CLARK, N.A. Potential of sunflowers for silage in double-cropping systems following small grains. Agronomy Journal, v.69, n.4, p.543-546, 1977.

SILVA, A.W.L.; MACEDO, A.F.; HOESCHL NETO, W. et al. Efeito da semeadura de densidade sobre a produtividade e composição bromatológica de silagens de girassol. In: REUNIÃO ANUAL DA SOCIEDADE BRASILEIRA DE ZOOTECNIA, 35., 1998, Botucatu. Anais... Botucatu: Sociedade Brasileira de Zootecnia, 1998. v.2, p.635-637.

SNEDDON, D.M.; THOMAS, V.M.; ROFFER, R.E. et al. Laboratory investigations of hydroxide-treatment sunflower or alfalfa-grass silage. Journal of Animal Science, v.53, n.6, p.1623-1628, 1981.

SOUZA, B.P.S. Momento de colheita de quatro genótipos de girassol (Helianthus annuus L.). Belo Horizonte: Universidade Federal de Minas Gerais, 2002.47p. Dissertação (Mestrado em Zootecnia) - Universidade Federal de Minas Gerais, 2002.

THOMAS, V.M.; MURRAY, G.A.; THACKER, D.L. et al. Sunflower silage in rations for lactating Holsteins cows. Journal of Dairy Science, v.65, n.2, p.267-270, 1982.

TILLEY, J.M.A.; TERRY, R.A. A two-stage technique for the "in vitro" digestion of forage crops. Journal of British Grassland Society, v.18, n.2, p.104-111, 1963.
TOSI, H.; SILVEIRA, A.C.; FARIA, V.P. et al. Avaliação do girassol (Helianthus annus) como planta para a ensilagem. Revista da Sociedade Brasileira de Zootecnia, v.4, n.1, p.39-48, 1975.

VALDEZ, F.R.; HARRISON, J.H.; DEETZ, D.A. et al. In vivo Digestibility of corn and sunflower intercropped as a silage crop. Journal of Dairy Science, v.71, n.7, p.1860-1867, 1988a.

VALDEZ, F.R.; HARRISON, J.H.; FRASEN, S.C. Effect of feeding sunflower silage on milk production, milk composition, and rumen fermentation of lactating dairy cows. Journal of Dairy Science, v.71, n.9, p.2462-2469, 1988b.

VANDERSALL, J.H. Sunflower silage for lactating dairy cows. Journal of Animal Science, v.42, n.6, p.1583-1584, 1976.

Van SOEST, P.J.; ROBERTSON, J.B.; LEWIS, B.A. Methods for dietary fiber, neutral detergent, and nonstarch polysaccharides in relation to animal nutrition. Journal of Dairy Science, v.74, n.10, p.3583-3597, 1991.

Van SOEST, P.J. Nutritional ecology of the ruminant. 2.ed. Ithaca: Cornell University Press, 1994. 476p.

VILELA, D. Aditivos para silagens de plantas de clima tropical. In: SIMPÓSIO SOBRE ADITIVOS NA PRODUÇ̃̃O DE RUMINANTES E NÃO RUMINANTES, 1., 1998, Botucatu, 35., REUNIÃO ANUAL DA SOCIEDADE BRASILEIRA DE ZOOTECNIA. Anais... Botucatu: Sociedade Brasileira de Zootecnia, 1998. p.73-108.

WALDO, D.R. Effect of forage quality on intake and forageconcentrate interactions. Journal of Dairy Science, v.69, n.2, p.617-631, 1986.

XICCATO, G.; CINETTO, M.; CARAZZOLO, A. et al. The effect of silo type and dry matter content on the maize silage fermentation process and ensiling loss. Animal Feed Science and Technology, v.49, n.3-4, p.311-323, 1994. 